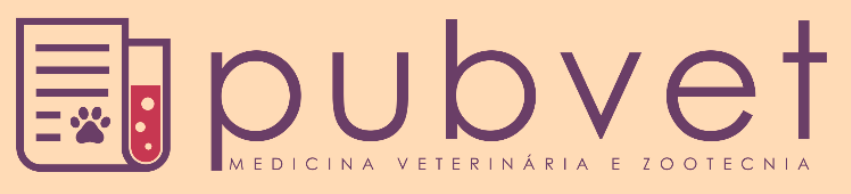

https://doi.org/10.31533/pubvet.v14n3a523.1-5

\title{
Do lixo ao luxo: Ecoempreendedorismo
}

\section{Lyara Suzhanny de Oliveira Santos ${ }^{1} \bullet$, Carlos Miguel Azarias dos Santos ${ }^{2 *} \bullet$, Janaína de Omena $\operatorname{Santos}^{3}{ }^{\circ}$, Josefa Eleusa da Rocha ${ }^{4} \bullet$}

${ }^{I}$ Graduanda do curso de ciências biológicas, Universidade Estadual de Alagoas - UNEAL, Arapiraca-AL Brasil.

${ }^{2}$ Graduando em ciências biológicas e pesquisador do grupo de extensão, Universidade Estadual de Alagoas-UNEAL e medicina veterinária, Faculdade Regional da Bahia - UNIRB, Arapiraca-AL Brasil.

${ }^{3}$ Graduada em geografia, Universidade Estadual de Alagoas-UNEAL, Arapiraca-AL Brasil.

${ }^{4}$ Professora e pesquisadora, do Curso de ciências biológicas, Universidade Estadual de Alagoas - UNEAL, Arapiraca-AL Brasil.

*Autor para correspondência, E-mail: carllos_miguel1@hotmail.com

Resumo. Nos últimos anos aumentando as preocupações com fatores ambientais devido às notórias de mudanças paisagísticas e climáticas nos diversos ambientes. Este artigo foi desenvolvido para avaliar o reaproveitamento do lixo produzido na escola com a coleta seletiva e utilizando o lixo reciclável de forma consciente e empreendedora. A pesquisa foi realizada com alunos do Colégio Alfa em Arapiraca. Foi utilizada a metodologia de segregação na fonte para coleta de lixo. A separação dos diferentes materiais recicláveis presentes no lixo foi realizada na fonte geradora. Para produção dos brinquedos foi utilizado o método de pesquisa na internet. No lixo produzido na escola foram encontrados percentuais dos seguintes materiais: Metal $-8 \%$, plástico $-30 \%$, papel $-20 \%$, orgânico $-11 \%$ e outros $-26 \%$. Os plásticos encontrados na escola foram: embalagens $-26 \%$, garrafas $-36 \%$, canudos $-3 \%$ - cd $2 \%$, tampas $-4 \%$ e outros $-29 \%$. Os papeis: folhas $-61 \%$ e caixas $-39 \%$. Os metais: Latas $-88 \%$ e lacres $-12 \%$. O trabalho mostra à comunidade escolar que o lixo quando bem selecionado pode trazer renda e redução de custos na sua coleta e diminuir o impacto ambiental. Desta forma, esse trabalho contribuiu para redução da quantidade de lixo produzido na escola e deu o destino certo a esse, além de produzir brinquedos lúdicos e educativos para melhorar a qualidade das atividades recreativas e acadêmicas na escola.

Palavras chave: empreendedorismo, lixo, educação ambiental

\section{From trash to luxury: Eco-entrepreneurship}

\begin{abstract}
Concerns have been increasing in recent years due to environmental factors due to the remarkable landscape and climate changes in the various environments. This article was developed to recycle solid waste in toys carried out with students from Alfa College in Arapiraca, where garbage collection was used at source segregation methodology, where the separation is performed at the source that generates the different types of recyclable materials present in the garbage. For the production of toys, it was used the research method on the internet. In the garbage produced at school were found percentages of the following materials: Metal $-8 \%$, plastic $-30 \%$, paper $-20 \%$, organic $-11 \%$ and other $-26 \%$. Plastics found in school were: packaging $-26 \%$, bottles $-36 \%$, straws $-3 \%$, cd $-2 \%$, caps $-4 \%$ and others $-29 \%$. The papers: $61 \%$ - sheets and $39 \%$ - boxes. Metals: cans $-88 \%$ and seals $-12 \%$. The work shows the school community that the waste when properly selected can bring income and cost reduction in its collection and reduce the environmental impact. Thus, this work contributed to reducing the amount of garbage produced in the school and gave it the right destination, in addition to producing playful and educational toys to improve the quality of school play and classes.
\end{abstract}

Keyword: entrepreneurship, garbage, environmental education 


\section{De la basura al lujo: Ecoemprendimiento}

Resumen. Las preocupaciones han aumentado en los últimos años debido a factores ambientales debido a los notables cambios en el paisaje y el clima en los diversos entornos. Este artículo fue desarrollado para reciclar desechos sólidos producidos en la escuela, el proyecto fue ejecutado con estudiantes del colegio Alfa en Arapiraca, donde se utilizó la metodología de segregación de fuente, realizando la separación directamente en la fuente generadora de diferentes tipos de materiales reciclables presentes en la basura. Para la producción de juguetes se utilizó el método de investigación en internet. En la basura se encontraron porcentajes de los siguientes materiales: metal $-8 \%$, plástico $-30 \%$, papel $20 \%$, orgánico $-11 \%$ y otro - $26 \%$. Plásticos encontrados en la escuela: embalaje $-26 \%$, botellas $-36 \%$, pajitas $-3 \%$, cd $-2 \%$, tapas $-4 \%$ e otros $-29 \%$. Los papeles: $61 \%$ - hojas y $39 \%$ - cajas. Metales: latas $-88 \%$ y sellos - $12 \%$. El trabajo muestro a la comunidad escolar que los desechos, cuando seleccionados adecuadamente pueden generar ingresos, reducción de costos en su recolección y al mismo tiempo reducción del impacto ambiental. Por lo tanto, este trabajo contribuyó para reducir la cantidad de basura producida en la escuela y le dio el destino correcto, además de producir juguetes lúdicos y educativos para mejorar la calidad de algunas actividades recreativas y académicas.

Palabra clave: emprendimiento, basura, educación ambiental

\section{Introdução}

Nas últimas décadas vêm aumentando as preocupações relacionadas às questões ambientais devido às modificações paisagísticas e climáticas nos diversos ambientes e, juntamente com isso, as iniciativas de diversos segmentos da sociedade, entre eles as escolas de educação básicas e universidades, para o desenvolvimento de ações e projetos com o objetivo de ensinar as comunidades, buscando conscientizálas para a modificação de comportamentos e posturas que beneficiem o equilíbrio do meio ambiente (Santos et al., 2019; Campos \& Santos, 2019; Mergulhão \& Vasaki, 1998).

O homem moderno precisa entender seu papel no mundo, que é de cuidar dos recursos naturais e fazer compreender essa relação homem versus planeta terra. O planeta precisa do homem para manter sua integridade - mesmo já não sendo na originalidade - e o homem precisa dos recursos naturais para sua sobrevivência (Ribeiro et al., 2007).

Segundo o Movimento Nacional de Catadores de Materiais Recicláveis (MNCMR), em torno de "1\% da população mundial sobrevive da coleta de materiais recicláveis". E quanto isso representa atualmente? Na busca da informação, esses $1 \%$ representam o quantitativo relevante de nada mais que aproximadamente 70 milhões de pessoas (Pinto, 2019).

O empreendedorismo torna-se uma peça-chave para essa modificação. O empreendedor sustentável, o empreendedor que tenta resolver problemas ambientais e sociais, além de gerar riqueza econômica, pode criar inovações que permitam lucros acima da média, ao mesmo tempo em que resolvam e/ou mitiguem os efeitos do comportamento do homem sobre o meio-ambiente (Carvalho \& Cohen, 2019).

O acúmulo de resíduos tornou-se uma grande preocupação aos órgãos públicos e a população de modo geral. Em virtude desta problemática, busca-se cada vez mais por métodos simples, quanto ao recolhimento e acondicionamento adequado dos resíduos, de forma a não causar prejuízos à população e ao meio ambiente (Barbosa et al., 2019). Devido à grande problemática que o lixo traz no tocante à poluição ambiental é de grande valia que seja realizada a coleta seletiva para que possa ser dado destino certo ao lixo produzido e assim possa reciclar o máximo possível e de forma sustentável esse lixo para que possa ser reutilizado, gerando renda e benefício para comunidade escolar e local. Desta forma, podese reaproveitar o lixo produzido na escola, fazendo a coleta seletiva e utilizar o lixo reciclável de forma consciente e empreendedora.

\section{Metodologia}

A coleta de lixo seletiva aconteceu no Colégio Alfa, localizada no município de Arapiraca no estado de Alagoas. Os dados foram coletados no período de abril a julho do ano de 2019. 
Para a coleta e seleção do lixo foi utilizada a metodologia de segregação na fonte, assim a separação foi realizada na fonte geradora dos diferentes tipos de materiais recicláveis presentes no lixo. A segregação do lixo foi feita pelos alunos participantes do projeto que acondicionaram os recicláveis separadamente (Figura 1). Esse lixo selecionado foi colocado em locais separados e foram pesados para que fosse feito a quantificação do lixo produzido na escola, depois os mesmos foram armazenados em locais adequados para cada tipo de material.

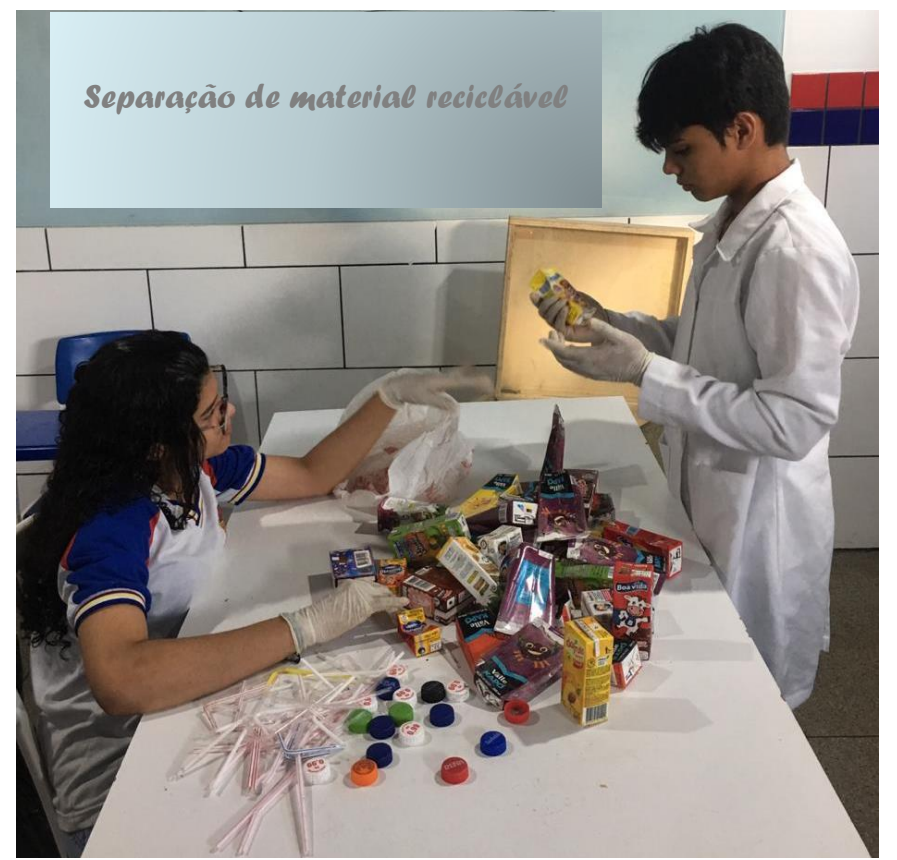

Figura 1. Alunos separando materiais recicláveis para fabricação de brinquedos

Para produção dos brinquedos foi utilizado o método de pesquisa na internet, realizando observações no intuito de conhecer brinquedos produzidos a partir de materiais recicláveis e estudando os processos de confecção e utilização desses brinquedos de forma lúdica e educativa.

Outro benefício que também foi adotado quanto à seleção do lixo foi à separação dos lacres das latas de refrigerantes, as quais foram armazenadas para que pudessem ser doada à instituição Confederação Nacional das Cooperativas Médicas (UNIMED) para que seja revertida em doação de cadeiras de rodas e assim ajudando a pessoas necessitadas.

\section{Resultados e discussão}

O lixo produzido na escola foi classificado, pesado e quantificado como mostra o gráfico 1. Podemos observar a quantidade de cada classe, dentre as que podem ser reciclados e as que devem ser descartadas.

No gráfico 1 podemos ver que a maior parte desse lixo foi plástico, seguido pelo papel e depois os metais. Os materiais orgânicos e os outros não foram utilizados na pesquisa, sendo assim foram descartados. Vale salientar que dentre os materiais orgânicos foi encontrada frutas, que não foram consumidas pelos alunos e colocadas intactas nos lixos.

Anjos et al. (2019) encontraram em sua pesquisa os materiais semelhantes ao encontrados na escola em estudo, como lixo, orgânico, seco, dentre outros, podendo ser reaproveitados, reciclados e ainda fazer uso da separação por coleta. Os alunos muitas vezes relacionam a educação ambiental como recolhimento de lixo, pois normalmente durante a semana do meio ambiente era essa a rotina: limpar o lixo gerado por eles (alunos) que estão em torno da escola, deixando os conceitos fundamentais de educação ambiental para trás (Rocha, 2019).

No gráfico 2 podemos observar a distribuição do plástico produzido na escola, onde $37 \%$ da quantidade de materiais plásticos eram oriundos de garrafas pet, as quais foram reutilizadas na confecção de brinquedos para uso na recreação dos próprios alunos e para comercialização na comunidade escolar. 
Entre os plásticos, também se destacaram os CD's descartados pela escola que foram utilizados na confecção de brinquedos e equipamentos para práticas de produção de energia. Os canudos e as tampas também foram reutilizados nas confecções de brinquedos. Aguiar et al. (2019) vão além com relação aos materiais encontrados na pesquisa em questão. A gama de resíduos plásticos descritos foram bem diversos, adotando a política dos 5 R's, onde foram bem vistos na educação ambiental.

\section{Lixo Produzido na Escola}

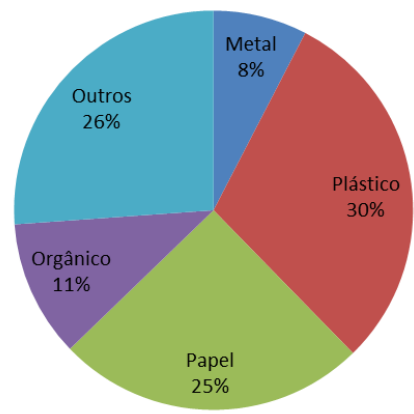

\section{Plástico Produzido na Escola}

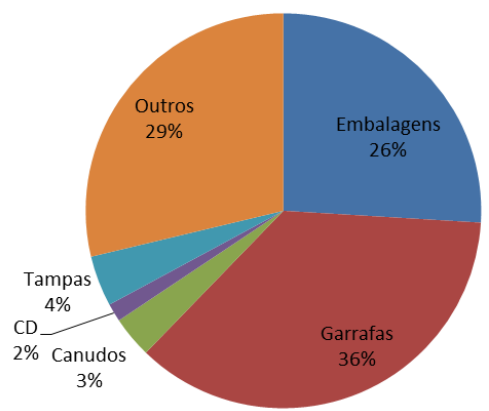

Gráfico 1. Lixo produzido no Colégio Alfa em Arapiraca-AL Gráfico 2. Plástico Produzido no Colégio Alfa em Arapiraca-AL

Assim como Bastos et al. (2019) as dificuldades encontradas na coleta foram semelhantes; porém, o que facilitou a execução deste projeto com escolares foram às boas práticas sobre o tratamento indicado, incentivo, curiosidade, engajamento e comprometimento do aluno na execução do trabalho.

O papel produzido na escola também foi separado e quantificado de acordo com o seu tipo para que fosse utilizado de maneira adequada. Como está expresso no gráfico 3, uma grande quantidade de caixas (suco, achocolatado etc.) foi encontrada no lixo. Essas caixas foram utilizadas na produção de carrinhos junto com as tampas de garrafas, entre outros brinquedos.

A reciclagem de papel, além de uma ótima alternativa para reaproveitamento de materiais é transformada na mesma matéria de origem, tendo a mesma finalidade. Campos \& Santos (2019) relataram sua experiência com essas atividades. E assim como toda e qualquer escola é capaz de ser encontrado em lixeiras folhas de cadernos já usados.

\section{Papel Produzido na Escola}

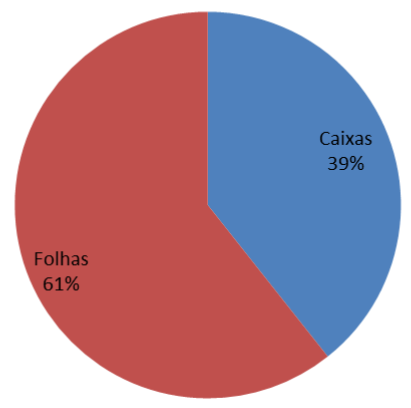

\section{Metal Produzido na Escola}

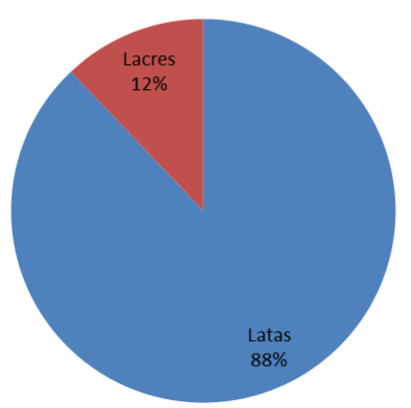

Gráfico 3. Papel Produzido no Colégio Alfa, Arapiraca-AL Gráfico 4. Metal Produzido no Colégio Alfa, Arapiraca-AL

As latas encontradas no lixo da escola foram utilizadas na produção de brinquedos e a comercialização para aquisição de recursos para manutenção sustentável do projeto, pois alguns materiais utilizados na produção dos brinquedos não foram encontrados no lixo da escola, necessitando, assim, sua aquisição. Já os lacres foram separados para doação.

Dentre os brinquedos produzidos pelos alunos podemos destacar a dama, o vai e vem, carrinhos, barquinhos, geradores de energia entre outros. 
Com o projeto estimulamos o espírito empreendedor dos alunos, pois a partir da comercialização das latas e de alguns dos brinquedos produzidos os mesmos conseguiram comprar novos materiais para fazer brinquedos diferentes. No entanto, o intuito principal do projeto foi a conscientização da comunidade escolar quanto o destino correto do lixo.

No decorrer do projeto, os alunos também visitaram as salas de aulas ministrando palestras aos outros alunos a respeito da conscientização e da coleta de lixo seletiva tanto na escola quanto nas residências, ensinando o destino correto que deve ser dado a cada tipo de lixo.

\section{Considerações finais}

O trabalho vem mostrar a comunidade escolar que o lixo quando bem selecionado pode trazer renda e redução de custos na sua coleta e diminuir o impacto ambiental. Desta forma, esse trabalho contribuiu para redução da quantidade de lixo produzido na escola e deu o destino certo a esse, além de produzir brinquedos lúdicos e educativos para melhorar a qualidade das brincadeiras e aulas da escola.

\section{Referências bibliográficas}

Aguiar, M. A. S., Santos, M. M. C., Barbosa, M. B. C., \& Almeida, R. M. (2019). A percepção sobre os resíduos sólidos dos alunos de uma escola pública de ensino médio em Santarém, Pará, Brasil. Educação Ambiental Em Ação, 69, 1-6.

Anjos, J. S., Wolff, G., Ferraro, A. C., \& Santos, C. F. (2019). Mobilização e implantação da coleta seletiva no município de Guanhães/MG. Revista Gestão \& Sustentabilidade Ambiental, 8(1), 600628.

Barbosa, A. P. F., Souza, R. C., Dias, J. F. M., Almeida, J. F. T., Borges, F. J., \& Freitas, I. C. (2019). Reaproveitamento de resíduos sólidos orgânicos oriundo da merenda escolar por meio da compostagem/Reutilization of organic solid waste from school meals through composting. Brazilian Applied Science Review, 3(2), 1161-1168.

Bastos, T. M., Bastos, E. H. O., Santos, S. M. silva, Santos, A. C., \& Barros, A. P. (2019). Ações socioambientais em escolas públicas da cidade de Rio Largo. Revista Psicologia \& Saberes, 8(10), 222-229.

Campos, F. L., \& Santos, R. A. (2019). Educação ambiental diante da problemática do lixo: uma análise descritiva em uma escola da área rural de Parnaíba - PI. Revista Ciências \& Ideias, 9(3), 80-93.

Carvalho, P. A. H. V, \& Cohen, M. (2019). Empreendedorismo sustentável enquanto empreendedorismo institucional: Estratégias de mobilização e de legitimação para a mudança. Revista Pretexto, 20(2), $122-140$.

Mergulhão, M. C., \& Vasaki, B. N. G. (1998). Educando para a conservação da natureza sugestões de atividades em educação ambiental. Editora EDUC.

Pinto, H. F. O. (2019). O catador de resíduos sólidos e sua função como empreendedor social numa visão contemporânea. Entrepreneurship, 3(1), 26-31.

Ribeiro, A. S. S., Palha, M. D. C., Tourinho, M. M., Whiteman, C., \& Silva, A. S. L. (2007). Utilização dos recursos naturais por comunidades humanas do Parque Ecoturístico do Guamá, Belém, Pará. Acta Amazonica, 37(2), 235-240.

Rocha, G. de O. (2019). A educação ambiental em uma escola pública no município de Osório-RS: um estudo de caso. In Estudo de caso. Universidade de Goiás.

Santos, P. V. S., Fernandes, C. H. A., \& Purificacao, M. R. R. G. (2019). A difusão da educação ambiental: um olhar sobre a região do vale do São Francisco. Revista Livre de Sustentabilidade e Empreendedorismo, 4(3), 54-72.

Recebido: 16 de outubro, 2019.

Aprovado: 22 de novembro, 2019.

Publicado: 22 de abril, 2020.

Licenciamento: Este artigo é publicado na modalidade Acesso Aberto sob a licença Creative Commons Atribuição 4.0 (CC-BY 4.0), a qual permite uso irrestrito, distribuição, reprodução em qualquer meio, desde que o autor e a fonte sejam devidamente creditados. 